\title{
Uluslararası Turist Gelişlerinin Kaba Küme Temelli Yaklaşımla Tahmin Edilmesi*
}

\author{
Mihrimah Özmen ${ }^{1 * *}$ \\ ${ }^{1}$ Endüstri Mühendisliği Bölümü / Erciyes Üniversitesi, Türkiye (ORCID: 0000-0002-2648-5865)
}

(Konferans Tarihi: 5-7 Mart 2020)

(DOI: 10.31590/ejosat.araconf11)

ATIF/REFERENCE: Özmen, M. (2020). Uluslararası Turist Gelişlerinin Kaba Küme Temelli Yaklaşımla Tahmin Edilmesi. Avrupa Bilim ve Teknoloji Dergisi, (Özel Say1), 80-87.

\section{$\ddot{O} \mathbf{z}$}

Turizm, uluslararası ticaretin önemli oyuncularından biri haline gelmektedir ve aynı zamanda birçok gelişmekte olan ülke için ana gelir kaynaklarından birini temsil etmektedir. Son yıllarda dünyanın en hızlı büyüyen ekonomik sektörlerinden biri olan turizm sektörü küresel gayri safi yurtiçi hasılaya yüzde 10' dan fazla katkı sağlayarak 10 işten 1 'ini oluşturmuştur. Sanayileşmiş ve gelişmiş ülkelerde turizmin küresel olarak yaygınlaşması, inşaattan tarıma, telekomünikasyona kadar ilgili birçok sektörde ekonomik ve istihdam katkı sağlamaktadır. Turizm sektörü büyümeyi ve kalkınmayı teşvik ederek, istihdam yaratarak, yoksulluğu azaltarak milyonlarca insanın hayatında fark yaratmaktadır. Böylelikle ekonomik büyümenin önemli güçlerinden biri olduğu kanıtlanmış ve ekonomik büyümeye önemli ölçüde katkı sağlamıştır. Turizmin ekonomik gelişmeye katkısı, sunulan hizmetinin kalitesine ve gelirine bağlıdır. Dünya Turizm Örgütü özellikle gelişmekte olan ülkelerin daha da karmaşık hale gelen ulusal ve uluslararası pazarlarda turizm sektörünün sürdürülebilir hale getirmenin önemini vurgulamaktadır. Emek yoğun bir sektör olan turizm sektöründe yer alan işletmeler ve bunların tedarikçileri turizm talebinin tahmin bilgisine ihtiyaç duymaktadır. Turizm talebinin doğru tahmin edilmesi, turizm işletmelerinin başarısı için son derece önemlidir. Literatürde, kaba küme teorisi, bilgi veri tabanının karmaşıklığını azaltmak için yaygın olarak kullanılan bir yaklaşımdır. Bu çalışmada, Dünya Ekonomik Forumu "Seyahat ve Turizm Rekabet Edebilirlik Endeksi" verilerinden uluslararası turist gelişleri kaba küme teorisine dayanan kural türetme algoritmasıly tahmin edilmiştir. Çalışmada ülkeler 88 nitelik için aldı̆̆ı değer bilgisi ışığında değerlendirilmiştir. Ülkelerin turist sayıları tahmininde kaba küme temelli kural türetme algoritması olan LEM2 algoritması uygulanmıştır. Uygulama sonucunda uluslararası turist gelişlerinin yüksek başarımla öngörebilen kurallar elde edilmiştir. Elde edilen sonuçlara göre kaba küme teorisine dayanan kural türetme algoritmaları uluslararası turist gelişlerinin ve davranış biçimlerinin öngörülmesini sağlayabilecek uygun bir yöntemdir.

\section{Rough Sets-Based Prediction Model For International Tourist Arrivals}

\begin{abstract}
Tourism is becoming one of the major players in international trade and also represents one of the main sources of income for many developing countries. Globalization of tourism in industrialized and developed countries contributes economically and employment in many related sectors from construction to agriculture to telecommunications. The tourism sector makes a difference in the lives of millions of people by promoting growth and development, creating jobs, reducing poverty. Thus, it has been proven to be one of the important powers of economic growth and has contributed significantly to economic growth. The contribution of tourism to economic development depends on the quality and income of the service. The World Tourism Organization emphasizes the importance of making the tourism sector sustainable, especially in national and international markets, which are becoming more complex in developing countries. Accurate prediction of tourism demand is of utmost relevance for the success of tourism businesses. In
\end{abstract}

\footnotetext{
* Bu makale International Conference on Access to Recent Advances in Engineering and Digitalization (ARACONF 2020) de sunulmuştur.

** Sorumlu Yazar: Endüstri Mühendisliği Bölümü / Erciyes Üniversitesi, Türkiye, ORCID: 0000-0002-2648-5865, mihrimah@erciyes.edu.tr
} 
literature, the rough set theory has been widely used approach to reduce the complexity of the knowledge database. In this study, it is aimed to predict international tourist arrivals with rule extraction algorithm based on rough set theory. "Travel and Tourism Competitiveness Index" dataset collected by the World Economic Forum were used. In the study, the rule extraction algorithm, LEM2, was applied to the dataset and the rules that can predict the arrivals of international tourists with high performance were obtained. According to the results obtained, rule derivation algorithms based on the rough set theory are an efficient method that can provide predictions of international tourist arrivals and behaviors.

Keywords: Tourism, International Tourist Arrivals, Rough Set Theory, Rule Extraction, Data Mining.

\section{Giriş}

Ülkeler, GSYİH katkısı sayesinde turizmden kazanmanın yanı sıra, özellikle otel/eğlence hizmetleri ile ilişkili sektörlerde birçok kişi istihdam edilmektedir. 2016 yılında uluslararası turist sayısı, 2015 yılına göre 46 milyon daha artarak 1,2 milyar gerçekleşmiştir. 2030 yılına kadar öngörülen 1.8 milyar uluslararası turist ile sektör, yüksek kaliteli istihdam firsatları yaratma ve insanlar, kültürler arasında köprüler kurma potansiyeline sahiptir. Araştırmalar her yeni 30 turistin yeni bir iş yarattığını göstermektedir ve turizm sektöründe diğer sektörlere göre neredeyse iki kat daha fazla kadın işveren çalışmaktadır. Dünya' da hizmet ihracatının \% 30'unu ve gelişmekte olan birçok ülkede en büyük ihracat kategorisini oluşturan sektör muazzam bir istihdam üreticisidir (Jackson ve Tamuke, 2019).

Turizm sektöründe talep tahmini, bir sonraki yılın planlaması ve politikalarının oluşturulmasında yardımcı bilgiler sağlaması açısından önemlidir. Literatürde yer alan turizm modellemesi ve turist sayısı tahmininde kullanılan yöntemler dört grupta incelenebilir: zaman serisi modelleri, ekonometri modelleri, yapay zeka teknikleri ve nitel yöntemler. Literatürde turistlerin davranış ve eğilimlerini yansıtan internet arama sorguları, turizm tahmin modellerinde giderek daha fazla kullanılmaktadır. Bununla birlikte, arama motoru indeksi turizm tahmininin modelleme sürecinde büyük firsatlar sağlamıştır (Li vd. 2017).

Veri madenciliği sınıflandırma algoritmalarında; bazı sistemlerdeki değişiklikler, kesin olmayan veya belirsiz değerler gibi sebeplerden dolayı kural elde edilmesinde bazı zorluklarla karşılaşılmaktadır. Bu zorlukların üstesinden gelmek için Kaba Küme temelli yöntemler uygulamaktır Skowron ve Dutta (2018), karmaşık sistemlerin modellenmesinde uygulanan Kaba Küme yaklaşımları ile verilerden anlamlı kuralların elde edilmesini sağlamıştır. Kaba küme temelli yaklaşımların geleneksel yöntemlere nazaran orijinal bilgilerin haricinde bilgi olmadan kullanılması, nicel ve nitel veri analizi, gizli bilgi ve kalıpların keşfedilmesi, anlaşılması kolay kurallar elde edilmesi gibi avantajları vardır (Dimitras, 2019 - Shen ve Loh, 2004).

Bu çalışmada kaba küme temelli sınıflama algoritması LEM2 ile Dünya Ekonomik Forumu Seyahat ve Turizm Rekabet Edebilirlik Endeksi verilerinden uluslararası turist sayılarının tahmin edilmiştir. Çalışmanın devamından ilk olarak önerilen model tanıtılmıştır. Sonraki bölümde ise önerilen model ile kural çıkarımı yapılıp sonuçları verilmiştir. Son bölümde ise çalışmanın literatüre katkısı ve gelecek çalışmalardan bahsedilmiştir.

\section{Materyal ve Metot}

\subsection{Kaba Küme Teorisi}

Z. Pawlak (1995, 1997), tarafından geliştirilen kaba küme teorisi, veri ve karar verme sürecindeki doğal belirsizliği yönetebilen bir matematiksel araçtır. kaba küme teorisi 30 yılı aşkın bir süredir incelenmekte ve makine öğrenimi, veri madenciliği, karar desteği, tahmin modelleme, süreç kontrolü, otomatik sınıflandırma vb. alanlarda kullanılmaktadır.

"Kaba küme analizi, Pawlak tarafından literatüre kazandırılan kaba küme teorisine dayanan bir matematiksel yaklaşımdır. Kaba kümenin amacı, belirsiz veri kaynaklarından bilgiyi keşfetmektir. Kaba küme teorisi, ayırt edilmezlik kavramı ve nesnelerin ayırt edilememesi üzerine kuruludur. Ayrıca hatalı verilerin ele alınmasına yönelik bir yaklaşım olarak kaba küme analizi; olasılık teorisi, kanıt teorisi ve bulanık küme teorisi gibi daha geleneksel teorileri tamamlamaktadır.

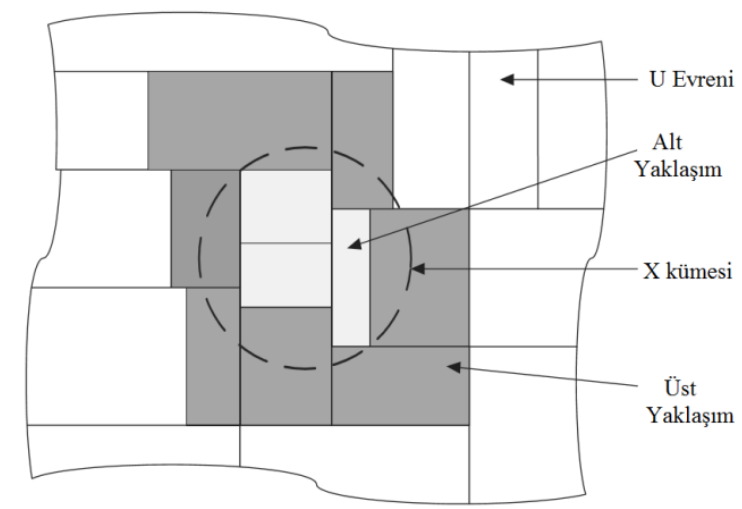

Şekil 1. Kaba Kümenin Gösterimi (Olson ve Delen, 2008)

Son yıllarda kaba küme teorisi, araştırmacılar için büyük bir ilgi konusu haline gelmiştir ve birçok alanda uygulanmıştır.” 
"Kaba küme teorisi; veri analizi için nesnelerin yaklaşık tanımlarını oluşturmada etkili bir tekniktir. Bir kaba küme; alt ve üst yaklaşımlar denilen bir çift kesin kavramlar tarafından tanımlanan belirsiz bir kavramın yaklaşımlarıdır. Bilgi içeriğini koruyarak gereksiz nitelikleri değerli veri kümelerinden çıkarmak için kaba küme kullanılmaktadır. Kaba küme teorisinde nitelik indirgemenin temeli ayırt edilemezlik kavramına dayanmaktadır. Bilgi sistemi $I=(U, A)$ ile ifade edilir ve $U$ boş olmayan örnek kümesini, $A$ boş olmayan nitelikler kümesini ve $\forall a \in A, V_{a}$ ise $a$ niteliğinin alabildiği değerler kümesini ifade eder (Jensen ve Shen, 2004).”

Karar sisteminde $A=\{C \cup D\}, C$ koşullu nitelikleri ve $D$ karar niteliğini göstermektedir. Herhangi bir $P \subseteq A$ ile ilişkili $I N D(P)$ şeklinde bir denklik ilişkisi vardır.

$\operatorname{IND}(P)=\left\{(x, y) \in U^{2} \mid \forall a \in P, a(x)=a(y)\right\}$

$I N D(P)$ tarafindan üretilen $U$ 'nun bölümü $U$ / $P$ olarak gösterilir ve aşağıdaki gibi hesaplanabilir:

$U / P=\bigotimes\{a \in P: U / I N D(\{a\})\}$,

$A \otimes B=\{X \cap Y: \forall X \in A, \forall Y \in B, X \cap Y \neq \emptyset\}$

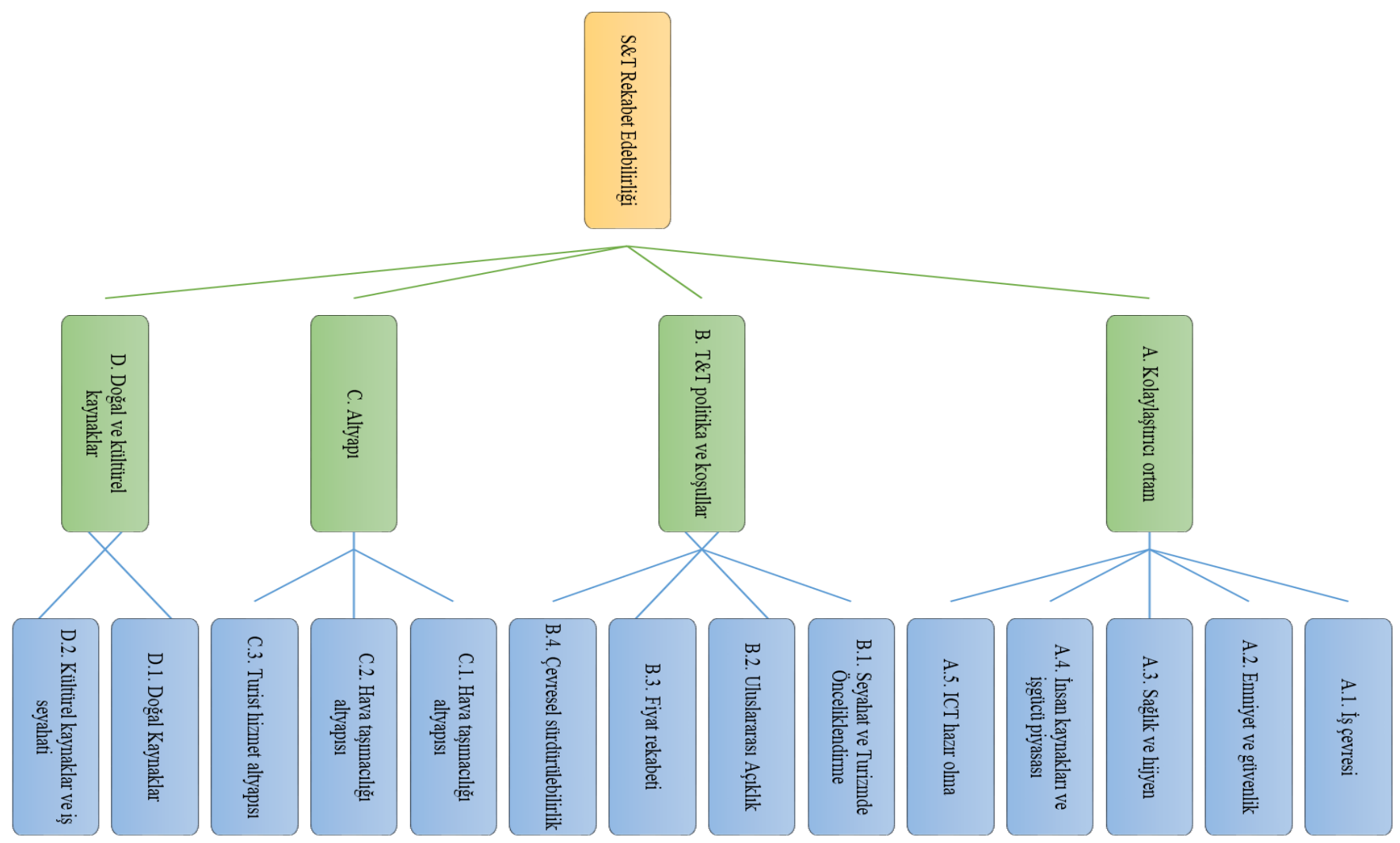

Şekil 2. Ülkelerin uluslararası turist gelişlerini etkileyen kriterler (Crotti ve Misrahi, 2017)

\section{2. Önerilen Kaba Küme Temellli Uluslararası Turist Sayısı Tahmin Modeli}

Önerilen uluslararası turist sayısı tahmin modeli bir dizi aşamadan oluşmaktadır. İlk aşamada veri setinin hazırlanması ve örneklenmesi yer almaktadır. Daha sonra hazırlanan veri seti veri temizleme ve ön işleme aşamasından geçerek veri madenciliği algoritmaları için uygun hale getirilir. Ön işleme aşamasından geçen veri setinden LEM2 algoritması ile kural çıkarımı gerçekleştirilir. Elde edilen kurallar uzmanlar tarafından incelenip listelenmiştir. Uzman bilgisi sonuçların gözden geçirilmesi, önemli bilgilerin belirlenmesi ve hangi bilgilerin gereksiz olduğuna karar verilmesinde de katkı sağlayabilir ve çok önemlidir.

\subsubsection{Veri Hazırlama ve Örnekleme}

Çalışmada, Dünya Ekonomi Forumu tarafından, "Seyahat ve Turizm Rekabet Edebilirlik Endeksi” için incelenen 136 ülkenin kapsamlı veri kümesi üzerinde çalışılmıştır. $\mathrm{Bu}$ veriler, ek temel göstergeler de dahil olmak üzere toplam 88 nitelik ile her ülkenin turizm sektörü hakkında tam bir bilgi sunmaktadır. Veri setinde yer alan niteliklerin hiyerarşik yapısı Şekil 2' de verilmiştir.

Hiyerarşik yapısı verilen nitelikler ve alt nitelikleri şöyledir:

A. Kolaylaştırıcı ortam

A.1 İş çevresi 
A1.1 Mülkiyet hakları

A1.2 Kuralların FDI üzerindeki etkisi

A1.3 Uyuşmazlıkların çözümünde yasal çerçevenin etkinliği

A1.4 Rejimlerde yasal çerçevenin etkinliği

A1.5 İnşaat izinleri için gereken süre

A1.6 İnşaat izinleri maliyeti (\% inşaat maliyeti)

A1.7 Pazar hakimiyeti kapsamı

A1.8 İşe başlamak için gün sayısı yok

A1.9 Bir işletme kurma maliyeti (kişi başına GSMG\% 'si)

A1.10 Vergilemenin çalışma teşvikleri üzerindeki etkisi

A1.11 Vergilemenin yatırım teşvikleri üzerindeki etkisi

A1.12 Toplam vergi oranı kâr yüzdesi

A.2 Emniyet ve güvenlik

A2.1 Suç ve şiddetin işletme maliyetleri

A2.2 Polis hizmetlerinin güvenilirliği

A2.3 Terörün işletme maliyetleri

A2.4 Terör olayı indeksi

A2.5 Cinayet vakalar1 / 100.000 nüfus

A.3 Sağllk ve hijyen

A3.1 Hekim sayıs1 / 1.000 nüfus

A3.2 Nüfusun iyileştirilmiş sanitasyon erişim yüzdesi

A3.3 Nüfusun gelişmiş içme suyuna erişimi olan yüzdesi

A3.4 Hastane yatakları / 10.000 kişi

A3.5 HIV prevalansı yetişkin kişi

A3.6 Sitma vakaları / 100.000 kişi

A.4 İnsan kaynakları ve işgücü piyasası

A4.1 İlköğretime kayıt net\%

A4.2 Ortaöğretime kayıt brüt\%

A4.3 Personel eğitiminin kapsamı

A4.4 Müşterilerin tedavisi

A4.5 İşe alma ve işten çıkarma uygulamaları

A4.6 Kalifiye eleman bulma kolaylığı (en iyisi)

A4.7 Yabancı iş̧̧i çalıştırma kolaylığı

A4.8 Ücret ve verimlilik

A4.9 Kadınların işgücüne katılımı erkeklere oranı

A.5 ICT hazir olma

A5.1 İşletmeler arası işlemler için BİT kullanımı

A5.2 İşletmelerden tüketiciye işlemler için internet kullanımı

A5.3 İnternet kullanan bireyler\%

A5.4 Sabit geniş bant İnternet abonelikleri / 100 kişi

A5.5 Cep telefonu abonelikleri / 100 kişi

A5.6 Aktif mobil geniş bant İnternet abonelikleri / 100 kişi 
A5.7 Mobil ağ kapsama oranı nüfus yüzdesi.

A5.8 Elektrik arz kalitesi

B. S\&T politika ve koşullar

B.1 Seyahat ve Turizmde Önceliklendirme

B1.1 Devletin seyahat ve turizm endüstrisine öncelik vermesi

B1.2 T\&T hükümet harcamaları

B1.3 Turistleri çekmek için pazarlama ve markalamanın etkinliği

B1.4 Yıllık T\&T verilerinin kapsamlılı̆̆ 1

B1.5 Zamanında Aylık / üç aylık S\&T verisi sağlama

B1.6 Ülke marka stratejisi değerlendirmesi

B.2 Uluslararası Açıklık

B2.1 Vize şartları

B2.2 İkili Hava Hizmet Anlaşmalarının Açıklığı

B2.3 Yürürlükteki bölgesel ticaret anlaşmalarının sayısı

B.3 Fiyat rekabeti

B3.1 Bilet vergileri ve havaalanı ücretleri

B3.2 Otel fiyat endeksi

B3.3 Satın alma gücü paritesi

B3.4 Yakıt fiyatı seviyeleri

B.4 Çevresel sürdürülebilirlik

B4.1 Çevre düzenlemelerinin sıkılığ

B4.2 Çevre düzenlemelerinin uygulanması

B4.3 Seyahat ve turizm endüstrisinin gelişiminin sürdürülebilirliği

B4.4 Partikül madde (2.5) konsantrasyonu

B4.5 Çevresel antlaşma onayı

B4.6 Temel su stresi

B4.7 Tehdit altındaki türler

B4.8 Orman örtüsü değişimi

B4.9 Atık su arıtma

B4.10 Kıyı balıkçılığı

C. Altyap1

C.1 Hava taşımacıllı̆̆ altyapısı

C1.1 Hava ulaşım altyapısının kalitesi

C1.2 Mevcut koltuk kilometre yerli

C1.3 Mevcut koltuk kilometreleri uluslararası

C1.4 Uçak Kalkışları

C1.5 Havaalanı yoğunluğu havaalanı / milyon kişi

C1.6 Havayolu sayıs1

C.2 Hava taşımacıllığı altyapısı

C2.1 Yolların kalitesi

C2.2 Demiryolu altyapısının kalitesi

C2.3 Liman altyapısının kalitesi 
C2.4 Kara taşımacılı̆̆ verimliliği

C2.5 Demiryolu yoğunluğu

C.3 Turist hizmet altyapısı

C3.1 Otel odalar1

C3.2 Turizm altyapısının kalitesi

C3.3 Büyük araç kiralama şirketlerinin varlığı (en iyi)

C3.4 100.000 yetişkin başına otomatik vezne makine sayısı

D. Doğal ve kültürel kaynaklar

D.1 Doğal Kaynaklar

D1.1 Dünya Mirası olan doğal yerlerinin sayısı

D1.2 Bilinen toplam tür

D1.3 Toplam korunan alanlar

D1.4 Doğal turizm dijital talebi

D1.5 Doğal varlıkların çekiciliği

D.2 Kültürel kaynaklar ve iş seyahati

D2.1 Dünya Mirası kültürel yerlerinin sayıs1

D2.2 Sözlü ve somut olmayan kültürel miras

D2.3 Spor stadyumları

D2.4 Uluslararası dernek toplantılarının sayısı

D2.5 Kültür ve eğlence turizmi dijital talebi

Her bir ülkenin yukarıda verilen 88 nitelik için aldığı değer bilgisi ışığında ülkelerin Dünya Bankası verilerine göre 2017 yılı uluslararası turist sayıları kaba küme temelli LEM2 algoritması ile tahmin edilmiştir (https://data.worldbank.org/).

\subsubsection{Veri Temizleme ve Ön işleme}

Veri madenciliğinde, anlamlı sonuçlara ulaşabilmek için veriyi ön işleme tabi tutulur. Bu nedenle verilerin temizlenmesi ve ön işlemden geçmesi önemli bir aşamadır. Genellikle, veri temizleme ve ön işleme, toplam veri madenciliği uğraşının yaklaşık \%80' ini oluşturur. Turizm veri kümesinde de eksik, gürültülü ve yanlış veriler yer almaktadır.

Veri kümesinde eksik verinin yer alması sık karşılaşılan bir sorundur. Eksik veri oranının \% 1'den az olması veri madenciliği kalitesi üzerinde etkisiz olarak kabul edilirken, eksik veri oranı \%1-5 arasında ise bu durumla başa çıkılabilir. Ancak bu oran \%5-15 arasında ise gelişmiş yöntemler uygulamak gerekmektedir (Acuna ve Rodriguez, 2004).

Önerilen modelde kullanılan veri setinin eksik veri oranı da dikkate alındığında, iyi sonuç elde edebilmek için veri temizleme ve ön işleme aşamasına ayrıca önem verilmiştir. Bu aşamada eksik değerler tamamlanmış ve hatalı veriler düzeltilmiştir. Bu aşamanın modele eklenmesiyle önerilen modele aynı zamanda eksik, gürültülü ve yanlış verilerin de üstesinden gelebilme yetisi kazandırılmıştır.

\subsubsection{Kaba Küme Temelli LEM 2 Algoritması ile Kural Çıkarımı}

$\mathrm{Bu}$ çalışmada kural elde etmek için LEM2 (Learning by Examples-Module 2) algoritması uygulanmıştır. ROSE-2 paket programında uygulanan LEM2 algoritması, kaba küme teorisinin alt yaklaşım kümesi ya da üst yaklaşım kümesine dayanan, veriden kural oluşturmada kullanılan denetimli tüm nesneleri kapsayan minimal bir kurallar dizisi üretir. LEM2 algoritmasının sahte kodu aşağıdaki gibidir (Sabu ve Raju 2011):

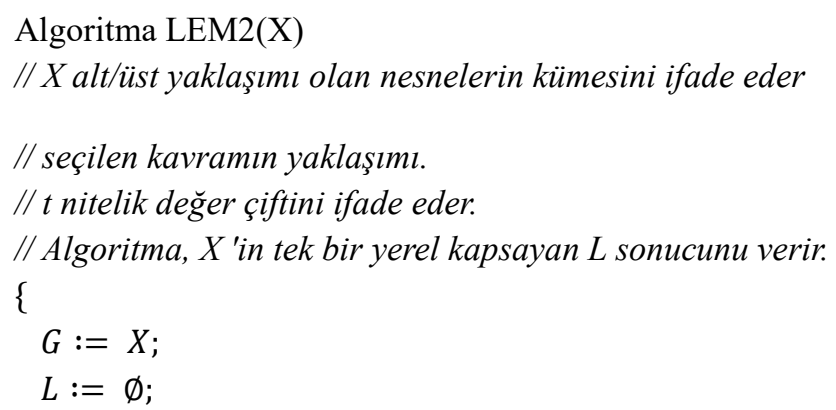




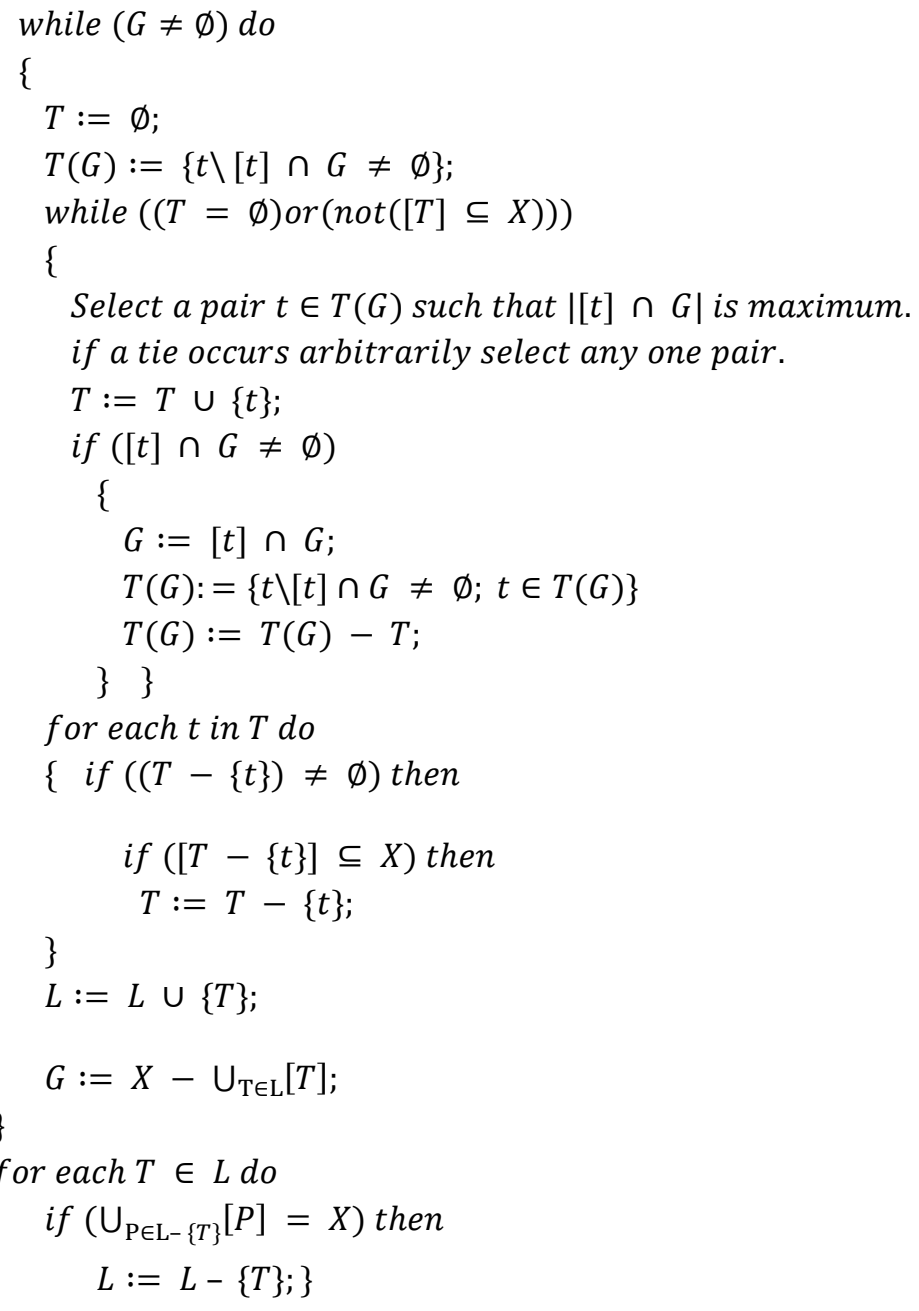

\section{Araştırma Sonuçları ve Tartışma}

Ön işleme tabii tutulmuş veri seti turistlerin ülkeleri tercih etmeleri hakkında kurallar oluşturmak için LEM2 algoritması uygulanmıştır. Turizm verileri sonuçlarına göre, 23 farklı kural elde edilmiştir. Bu kurallar aşağıda listelenmiştir.

1) A2.4 $>=6.4$ ve D2.1 $<=4.7$ ve D2.4 $<=92.6$ ise uluslararası turist sayıs 8.8 milyondan daha azdir.

2) $\mathrm{A} 3.3>=95.08$ ve $\mathrm{B} 1.5>=20.25$ ve $\mathrm{C} 1.5<=2.69$ ve $\mathrm{C} 3.2>=5.62$ ve $\mathrm{C} 3.2<=6$ ise uluslararas1 turist sayıs1 34.8 milyon-43.4 milyon arasindadır.

3) $\mathrm{B} 2.3>=47.8$ ve $\mathrm{B} 4.7>=5.13$ ve $\mathrm{B} 4.7<=8.69$ ve $\mathrm{C} 1.3<=1299.72$ ve $\mathrm{C} 1.5<=2.69$ ise uluslararas turist say1s1 8.8 milyon -17.4 milyon arasindadir.

4) $\mathrm{A} 2.3>=5.47$ ve A2.3 $<=5.88$ ve $\mathrm{B} 1.6<=35.96$ ve $\mathrm{C} 1.5<=2.69$ ve D1.2 $>=415.1$ ve D1.2 $<=734.2$ ise uluslararas1 turist say1S 1 8.8 milyon- 17.4 milyon arasındadir.

5) $\mathrm{A} 1.5>=90.4$ ve A1.5 $<=152.8$ ve $\mathrm{B} 4.9>=50$ ve B $4.9<=60$ ise uluslararasi turist sayıs 8.8 milyon- 17.4 milyon arasindadır.

6) $\mathrm{B} 4.4>=5.26$ ve $\mathrm{B} 4.4<=9.92$ ve $\mathrm{C} 1.5<=2.69$ ve $\mathrm{C} 3.2>=4.84$ ve $\mathrm{C} 3.2<=5.23$ ise uluslararas1 turist sayıs 8.8 milyon-17.4 milyon arasindadir.

7) $\mathrm{A} 1.9<=15.98$ ve $\mathrm{B} 4.3>=3.65$ ve $\mathrm{B} 4.3<=4.02$ ve $\mathrm{C} 1.6>=2599.13$ ve $\mathrm{C} 1.6<=3898.55$ ise uluslararas1 turist sayıs 8.8 milyon17.4 milyon arasindadır.

8) $\mathrm{A} 1.9<=15.98$ ve $\mathrm{B} 4.7>=5.13$ ve $\mathrm{B} 4.7<=8.69$ ve $\mathrm{B} 4.9>=50$ ve $\mathrm{B} 4.9<=60$ ise uluslararasi turist sayıs 8.8 milyon-17.4 milyon arasindadir.

9) $\mathrm{B} 3.1>=60$ ve $\mathrm{B} 3.1<=70$ ve $\mathrm{C} 1.6>=45$ ve $\mathrm{C} 1.6<=67$ ise uluslararası turist sayıs 8.8 milyon-17.4 milyon arasındadır.

10) $\mathrm{A} 5.3>=79.1$ ve $\mathrm{A} 5.3<=88.65$ ve $\mathrm{B} 1.2>=779.86$ ve $\mathrm{B} 1.2<=1008.43$ ve $\mathrm{C} 3.3>=6.4$ ve $\mathrm{D} 2.2<=3.9$ ise uluslararasi turist say1S1 8.8 milyon-17.4 milyon arasindadır.

Örneğin Kural-1 ülkenin A2.4 Terör olayı indeksi 6.4 değerinden daha büyük ve D2.1 Dünya Mirası kültürel yerlerinin sayıs1 4.7 değerinden daha küçük ve D2.4 Uluslararası dernek toplantılarının sayısı 92.6 değerinden daha küçük ise uluslararası turist sayısı 8.8 milyondan daha azdır. 9. Kural ise ülkenin B3.1 Bilet vergileri ve havaalanı ücretleri değeri 60 ila 70 arasında ve C1.6 Havayolu 
sayıs1 45-67 değerleri arasında ise uluslararası turist sayısı 8.8 milyon-17.4 milyon arasındadır. Kural 2 ise ülkenin A3.3 Nüfusun gelişmiş içme suyuna erişimine olan yüzdesi 95.08 değerinden daha büyük ve B1.5 Zamanında aylık / üç aylık S\&T verisi sağlama değeri 20.25 ' den daha büyük ve C1.5 Havaalanı yoğunluğu havaalanı / milyon kişi 2.69 değerinden daha küçük ve C3.2 Turizm altyapısının kalitesi 5.62-6 değerleri arasında ise uluslararası turist sayısı 34.8 milyon-43.4 milyon arasındadır.

\section{Sonuç}

Bu çalışmada, 136 ülkeye ait 2017 yılı turizm verileri önerilen modele göre sınıflandırılmıştır. Turist hacminin doğru tahmin edilmesi turizm sektörünün kaynaklarını daha doğru tahsis etmelerine ve fiyatlandırma stratejilerini daha gerçekçi olarak belirlemelerine katkı sağlaması açısından önemlidir. Sadece turizm sektörüne değil aynı zamanda turizmin bağlı olduğu sektörleri de doğrudan veya dolaylı olarak katkıda bulunabilir. Bunların yanı sıra turist hacminin eğilimlerini öngörebilmek; politika kararlarının ayarlanmasına, turizm konut planlaması ve ulaşım sistemi için altyapı tasarlamasına da katkı sağlaması açısından da önemlidir.

\section{Kaynakça}

Acuna, E., \& Rodriguez, C. (2004). The treatment of missing values and its effect on classifier accuracy. In Classification, clustering, and data mining applications (pp. 639-647). Springer, Berlin, Heidelberg.

Crotti, R., \& Misrahi, T. (2017). The travel \& tourism competitiveness report 2017. Paving the way for a more sustainable and inclusive future. In World Economic Forum: Geneva, Switzerland (p. 2017).

Dimitras, A. I., Slowinski, R., Susmaga, R., \& Zopounidis, C. (1999). Business failure prediction using rough sets. European Journal of operational research, 114(2), 263-280.

https://data.worldbank.org/

Jackson, E. A., \& Tamuke, E. (2019). Predicting disaggregated tourist arrivals in Sierra Leone using ARIMA model.

Jensen, R., \& Shen, Q. (2004). Fuzzy-rough attribute reduction with application to web categorization. Fuzzy sets and systems, 141(3), 469-485.

Li, X., Pan, B., Law, R., \& Huang, X. K. (2017). Forecasting tourism demand with composite search index. Tourism Management, $59,57-66$

Olson, D. L., \& Delen, D. (2008). Advanced data mining techniques. Springer Science \& Business Media.

Pawlak, Z., Grzymala-Busse, J., Slowinski, R., \& Ziarko, W. (1995). Rough Sets, Communications of the ACM. Emerg. Technol. AI, 38(11), 89-95.

Pawlak, Z. (1997). Rough set approach to knowledge-based decision support. European journal of operational research, 99(1), 48-57.

Sabu MK, Raju G, (2011) Rule induction using Rough Set Theory-An application in agriculture. In 2011 Int. Conf.on Comp Com. and Elect.1 Tech. (ICCCET) IEEE, p. 45-49.

Shen, L., \& Loh, H. T. (2004). Applying rough sets to market timing decisions. Decision support systems, 37(4), 583-597.

Skowron, A., \& Dutta, S. (2018). Rough sets: past, present, and future. Natural computing, 17(4), 855-876.

Sun, S., Wei, Y., Tsui, K. L., \& Wang, S. (2019). Forecasting tourist arrivals with machine learning and internet search index. Tourism Management, 70, 1-10. 